\title{
Integrated highland wildfire, smoke, and haze management in the Upper Indochina region
}

\author{
Kobsak Wanthongchai $^{\mathrm{a}}{ }^{*}$, Veerachai Tanpipat $^{\mathrm{a}}{ }^{(\mathbb{C})}$, Prayoonyong Noochaiya $^{\mathrm{b}}$, \\ Nion Sirimongkonlertkun ${ }^{\mathrm{c}}$, Ronald Macatangay ${ }^{\mathrm{d}}{ }^{(\mathbb{C})}$, Lattana Thammavongsa $^{\mathrm{e}}$, Thaung Naing $\mathbf{O o}^{\mathrm{f}}$, \\ Sherin Hassan Bran ${ }^{\mathrm{d}}$, Raman Solanki ${ }^{\mathrm{d}}$ \\ ${ }^{a}$ Upper ASEAN Wildland Fire Special Research Unit, Faculty of Forestry, Kasetsart University, Chatuchak, Bangkok, \\ Thailand \\ ${ }^{\mathrm{b}}$ Department of National Park, Wildlife and Plant Conservation, Chatuchak, Bangkok, Thailand \\ ${ }^{\mathrm{c}}$ Rajamangala University of Technology, Chiang Rai, Thailand \\ ${ }^{d}$ National Astronomical Research Institute of Thailand, Chiang Mai, Thailand \\ ${ }^{e}$ Department of Forestry, Ministry of Agriculture and Forestry, Vientiane Capital, Lao PDR \\ ${ }^{\mathrm{f}}$ Forest Research Institute, Forest Department, Ministry of Environmental Conservation and Forestry, Nay Pyi Taw, \\ Myanmar \\ * Corresponding author. Email: fforksw@ku.ac.th.
}

\section{ABSTRACT}

Fire has long been used in Southeast Asia for the purposes of cooking, protection, and warmth. However, climate change and economic pressure have modified the life of locals, including fire practices in daily life and other fire uses. The land use of forest cover in highland area (mostly deciduous forest) has shifted to cultivation, with the application of slash-and-burn techniques. This results in frequent unplanned fires causing pollution in the form of smoke and haze. A zero-burn policy has been implemented to tackle this problem but such a policy may not be appropriate as people still need fire as a basic tool for agriculture land preparation. Moreover, the deciduous forest is a fire-dependent ecosystem to maintain its ecosystem. Frequent burning by local people or excessive government intervention in preventing fires can impact this ecosystem. In the highlands, shifting cultivation has gradually been replaced by rotational agricultural practice with a cycle of 2 to 5 years. However, the fuel load for a 2-year rotation period is only 0.25 $\mathrm{t} \mathrm{ha} \mathrm{a}^{-1}$ higher than that of a mixed deciduous forest. New fire risk maps classified according to forest types were produced for Thailand, Lao PDR, and Myanmar. We report that the mixing layer (ML) height in Chiang Mai Province was, on average, $500 \mathrm{~m}$ during March, with common occurrence of subsidence inversion resulting in further lowering of air quality during this month. A participatory process to develop a Community Based Fire Management (CBFiM) was undertaken and it was observed that a successful implementation would need a community with a strong leadership.

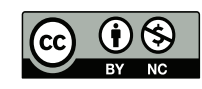

(C) The authors LICENCE This work is licensed under a Creative Commons Attribution NonCommercial 4.0 International License.

DOI 10.30852/sb.2021.1704

RECEIVED 30 August 2021 PUBLISHED (HTML) 21 December 2021

PUBLISHED (PDF) 21 December 2021

CITATION Wanthongchai, K., Tanpipat, V., Noochaiya, P., Sirimongkonlertkun, N., Macatangay, R., Thammavongsa, L., ... Solanki, R. (2021). Integrated highland wildfire, smoke, and haze management in the Upper Indochina region. APN Science Bulletin, 11(1), 133-143. doi: 10.30852/sb.2021.1704

\section{KEYWORDS}

Highlands, Rotated Agriculture, Fuel Load, Fire Risk Maps, Mixing Height, CBFiM 


\section{HIGHLIGHTS}

- A better understanding of fuel load and fire behaviour in the highlands of upper ASEAN Region.

- Fire risk maps for Thailand, Lao PDR, and Myanmar.

- Short-term air quality forecast for the Chiang Mai Province.

- Good community-based fire management practices.

- International collaboration between Thailand, Lao PDR, Myanmar and Asian Forest Cooperation Organization (AFoCO).

\section{INTRODUCTION}

Fire has long been used in Southeast Asia for purposes of cooking, protection and warmth. However, climate change, population increase and economic pressures have changed the way locals live, in terms of fire rituals practiced in their daily life, its cultural uses or the way indigenous people use fire for their livelihood, such as using fire for gathering non-timber forest products, using fire to clear land for agriculture, etc. Forests are burned too frequently to harvest non-timber forest products (NTFPs). The land use character of highland areas has been gradually changing from forest cover (mostly deciduous forest) to shifting cultivation, in which the slash-and-burn technique is readily applied. Subsequently, crop rotation practice has been employed in such locations, where a few fixed plots will be used over the coming years. This has led to frequent unplanned fires and hence air pollution caused by smoke. For example, most forest fires lit in the highland areas of northern Thailand are for harvesting of NTFPs and open burning in fields practicing monoculture, such as maize. This creates air quality problems during the fire season between February and April, with the peak burning period in March. In Thailand, a zero-burn policy with a prohibited burning period has been enforced to tackle this problem. However, this policy may not be appropriate, since people still need fire in agriculture, as it is the cheapest way to clear the land and prepare it for the next crop. However, the last forest fire in 2019 indicated to the ill-effects of this practice, when, unfortunately, more unplanned fires led to conflicts between locals and government authorities. Moreover, the deciduous forest is a firedependent ecosystem; frequent burning by locals or too much intervention by the government policy can impact this ecosystem. This project adopts an Integrated Fire Management (IFM) system with a participatory process involving people to develop a Community Based Fire Management (CBFiM) plan. To achieve this target, fuel and fire behaviour, fire impact, fire risk map derived from fire meteorology and air pollutant emissions, climatology, modelling, and climate change scenarios were evaluated. Community participation is an essential factor while considering the aforementioned information for developing a suitable and sustainable CBFiM plan.

\section{METHODOLOGY}

\subsection{Sampling of plots to study fuel and fire} behaviour across various land use types

Pre-burned fuel characteristics were complied selected in a swidden farm (with 1- and 5-year fallow periods), a corn farm, upland rice farm, an abandoned highland (natural restoration area) and a mixed deciduous forest in Nan and Huai Kha Kang (HKK) Forest Fire Research Center, Thailand. Fuel loads in the 1- and 5-yr swidden farms comprised 
of litter and herbs, as well as trees and shrubs given that the agricultural practices employed in the highland areas. Such slash and burn practices result in the cutting and burning of these woody plants. Therefore, we included the woody plants as available fuel. The quantity of fuel was estimated using the equations of Tsutsumi, Yoda, Sahunalu, Dhanmanonda, and Prachaiyo (1983).

Fire behaviour experiments were set up to determine the flame length, rate of fire spread, and fire intensity based on the equations recommended by Byram (1959), whereas forest fuel and corn stubble heat values were obtained from Sompoh (1998) and Lizotte, Savoie, and Champlain (2015), respectively.

\subsection{Highland fire risk map across northern}

Thailand, Myanmar, and Lao PDR

Data needed for the construction of fire risk maps for the highlands in the upper ASEAN region were compiled from various sources. These included the Land Cover Product from the European Space Agency Climate Change Initiative, Active Fire Products from NASA-FIRMS (National Aeronautics and Space Administration-Fire Information for Resource Management System), Global Forest Watch Fire by the World Resources Institute, Global Forest Change data maintained by the Department of Geographical Science, University of Maryland, MCD64A1.006 MODIS Burned Area Monthly Global 500m by EarthMap-FAO, and Fire emissions derived from the Fire Radiative Power (FRP) product of the European Centre for Mediumrange Weather Forecasts (ECMWF)-Copernicus Atmosphere Monitoring Service (CAMS)-Global Fire Assimilation System. Data was then regrouped into similar classes to simplify the land cover maps and projected on to the country's land cover map. MODIS active fire products from 2001 to 2019 were separated based on various satellites, years, and months, to determine the fire regimes and fire ignition patterns. The Mosaic and Global Land Analysis and Discovery (GLAD) Forest 'loss year' products during the years 2001-2018, were used to observe the forest loss patterns. Lastly, the data was analyzed and risk maps by forest type were created.

\subsection{Understanding the meteorology and air} pollutant emissions from fire in the study domain through climatology, measurements, modelling and climate change scenarios

The atmospheric boundary layer, also referred to as the planetary boundary layer or mixing layer (ML), is a turbulent layer located at the lowest part of the atmosphere that is in a constant state of exchange (i.e., diurnal cycles of heat, water vapour, and pollutant exchange) with the surface of the Earth (Stull, 1988; Seibert, 2000). The temporal response range usually lies within a scale of an hour or less.

Estimating the height of the ML can be done using Light Detection and Ranging (LiDAR). LiDAR operates by shooting a pulsed laser of particular wavelength (in this case, a wavelength of $532 \mathrm{~nm}$ ) vertically into the atmosphere. Backscattering occurs when the laser pulse encounters aerosols, particulates suspended in the atmosphere, or clouds, with the number of photons, as a function of height or altitude (range), detected by the ground system. The number of photons detected is proportional to the aerosol content along the light path of the laser.

The study utilized a mobile atmospheric micropulse LiDAR owned and operated by the Atmospheric Research Unit of the National Astronomical Research Institute of Thailand (ARUNARIT or ARUN), located at the NARIT headquarters in the Maerim district of Chiang Mai, northern Thailand $\left(18.8510^{\circ} \mathrm{N}, 98.9580^{\circ} \mathrm{E}, 472 \mathrm{masl}\right)$. It has been operational at the given location since April 2017 and has been part of the NASA Micropulse LiDAR Network (MPLNet) since August 2018 (https: //mplnet.gsfc.nasa.gov/data.cgi?site=Princess_Siri ndhorn_AstroPark).

From February-September 2019, the micropulse LiDAR was relocated to the Fang district, in north of Chiang Mai, northern Thailand (https://mplnet.gsfc.nasa.gov/data.cgi?site=Fan g; $19.9110^{\circ} \mathrm{N}, 99.2020^{\circ} \mathrm{E}, 472$ masl) near the border of Myanmar (approximately $14 \mathrm{~km}$ ) and 
in proximity to Lao PDR (approximately $100 \mathrm{~km}$ ), as a part of the profiling with LiDAR and UAV Multi-scale Experiment (PLUME) and the Spring 2019 Seven Southeast Asian Studies (7-SEAS) measurement campaign in March 2019. Apart from the atmospheric LiDAR instrument, PLUME partners from the Department of Atmospheric Science of the National Central University of Taiwan also deployed black carbon measurements onboard a UAV. In this research, the height of the ML was estimated using the Haar Covariance Wavelet Transform (Brooks, 2003; García-Franco, Stremme, \& Bezanilla, 2018), which is a de-noising and gradient detection method wherein it estimates the ML height by determining the altitude at which there is a maximum gradient of the LiDAR backscatter signal.

A lecture was also presented regarding this topic during workshops organized by the proponents.

\subsection{People's participation in the management of fire and smoke using concepts of Integrated Forest Fire Management (IFFM)}

We used a desktop study and literature review to gather documents, information, publications and evidence about the history of the community, their traditions and way of life. In addition, participatory observation was used to observe the conditions of the study areas and the community activities related to the management of forest fire. We also conducted in-depth interviews to understand and assess the lessons learned from the community about forest fire and haze management. Focus group discussions were organized, where the target audience (i.e., the sub-district headmen, village headmen, community leaders and youth leaders) were asked about their awareness of forest fire and haze pollution and their roles or participation in addressing the problem, together with support from the government sector and civil society organizations. Informal dialogues took place during discussions with the community members and the interviewers would ask for more detail, if any interesting topics related to forest fire management came up.

\section{RESULTS AND DISCUSSION}

\subsection{Fuel and fire behaviour in sample plots across} various of land use in the highlands

Common agricultural practices in the highlands include swidden farm agriculture using slash-andburn practices. Upland rice growing is the most important cash crop for the swidden farms. All vegetation is duly cut before the commencement of the cropping season (January-February). The burning period usually starts around early March for the preparation of land. Prior to burning, farmers apply firebreaks around the land and ask for the assistance of the forest fireguards in controlling the fire. Burning is, therefore, safely operated through this controlling strategy. Usually, villagers cultivate rice for 1 to 2 growing seasons and then leave the land for a couple of years. In the past, the period of rotation used to be seven years, but the fallow period was shortened to 2 to 5 years due to a limited availability of agricultural land. As for other cash crops, such as corn and cabbage, the villagers do not leave the land fallow for any period anymore. We observed that semi-permanent agriculture is adopted for corn and cabbage cultivation in the highland areas of Thailand. After harvesting, the farmers leave the agricultural residue (stubble) on the land and burn it when the weather and fuel conditions are favourable.

\subsubsection{Fuel characteristics}

The study demonstrated that above-ground pre-burned fuel structures on the corn farm and the mixed deciduous forest consisted of both litter and undergrowth. Fuel loads in the corn farm were composed of $3.59 \mathrm{t} \mathrm{ha}^{-1}$ of stubble litter and $0.27 \mathrm{t}$ $\mathrm{ha}^{-1}$ of undergrowth, with a fuel height of $0.34 \mathrm{~m}$ and $0.41 \mathrm{~m}$, respectively. On the other hand, fuel in the mixed deciduous forest comprised $3.34 \mathrm{tha}^{-1}$ of litter and 0.23 tha $^{-1}$ of undergrowth with an average fuel height of $0.30 \mathrm{~m}$ and $0.43 \mathrm{~m}$, respectively. Undergrowth contributed the most to the available fuel in the swidden farms, abandoned areas and upland rice farms. Interestingly, the 5-year swidden farm had a very large amount of fuel load (110 t 


\begin{tabular}{|c|c|c|c|c|c|c|}
\hline \multirow[t]{2}{*}{ Study site } & \multirow[t]{2}{*}{ Land use } & \multicolumn{2}{|c|}{ Fuel height (m) } & \multicolumn{3}{|c|}{ Pre-burned fuel (t ha ${ }^{-1}$ ) } \\
\hline & & Litter & Undergrowth & Litter & $\begin{array}{l}\text { Undergrowth } \\
\text { and tree }\end{array}$ & Total \\
\hline \multirow[t]{7}{*}{ Nan province } & Corn farm & $0.34 \pm 0.12$ & $0.41 \pm 0.02$ & $3.59 \pm 0.49$ & $0.27 \pm 0.50$ & $3.86 \pm 0.47$ \\
\hline & Upland rice farm & NA & $0.48 \pm 0.08$ & NA & $2.665 \pm 0.49$ & $2.665 \pm 0.49$ \\
\hline & 1-yr swidden farm & $0.14 \pm 0.05$ & $2.18 \pm 0.38$ & $3.00 \pm 0.26$ & $7.9375 \pm 2.01$ & $10.93 \pm 2.89$ \\
\hline & 5-yr swidden farm & $0.19 \pm 0.09$ & $0.35 \pm 0.08$ & $3.625 \pm 0.36$ & $106.75 \pm 35.28$ & $110.37 \pm 48.41$ \\
\hline & Abandoned & $0.15 \pm 0.05$ & $2.54 \pm 1.95$ & $17.83 \pm 1.22$ & $33.26 \pm 13.52$ & $51.10 \pm 16.25^{*}$ \\
\hline & highland & & & & & \\
\hline & $\begin{array}{l}\text { Mixed deciduous } \\
\text { forest }\end{array}$ & $0.12 \pm 0.04$ & $0.43 \pm 0.14$ & $3.34 \pm 0.29$ & $0.23 \pm 0.15$ & $3.57 \pm 0.39^{*}$ \\
\hline
\end{tabular}

Remark: * trees were not included. NA implies not applicable.

TABLE 1. Fuel characteristics in the highland areas of Thailand.

$\mathrm{ha}^{-1}$ ), whereas the abandoned area (under natural restoration) had less than half that amount $(51 \mathrm{t}$ $\mathrm{ha}^{-1}$ ) (Table 1). This is probably because woody plants in the natural restoration area were not included.

\subsubsection{Fire behaviour}

The results in Table 2 indicate that the rate of fire spread in the corn farm $\left(5.61 \mathrm{~m} \mathrm{~min}^{-1}\right)$ was higher than in the mixed deciduous forest $(4.68 \mathrm{~m}$ $\left.\mathrm{min}^{-1}\right)$. The speed with which the fire spread in the abandoned area and in the 5-year swidden farm, however, was relatively low. In the abandoned area, fuel moisture content was high, while heavy fuel (slashed logs) was observed in the swidden farm, resulting in a lower rate of spread (ROS) in the area. It was found that the fire intensity in the 5year swidden farm was highest, followed by the abandoned area. The average flame length was also the highest in the swidden farm, reaching about $12 \mathrm{~m}$, while the flame length in the corn farm reached only about $1.5 \mathrm{~m}$. A higher fire intensity in the swidden farm could be explained by a higher fuel load, high temperature, high wind speed, and lower relative humidity during the duration of the prescribed fire experiment. The fuel distribution was also a factor contributing to a higher rate of fire spread, intensity, and flame length.

According to the fire intensity scale developed by Andrews (1980), the scale of fire intensity in this study was medium. In contrast, when applying the forest fire rating scale developed by Akaakara (1996), the fire intensity in the corn farm and mixed deciduous forest in Nan province was more than $301.03 \mathrm{~kW} \mathrm{~m}^{-1}$ and was classified as high (danger). Fire intensities calculated in this study were also compared with other studies in similar ecosystems. Wanthongchai, Tarusadamrongdet, Chinnawong, and Sooksawat (2013) reported that the fire intensity in a degraded pine forest of Nam Nao National Park, Petchabun province, was 626.60 $\mathrm{kW} \mathrm{m}^{-1}$, which is higher than that reported in this study. This could be because the degraded pine forest had more fuel load, mainly composed of grass and leaves ( $45.40 \%$ and $44.35 \%$, respectively). In contrast, Junpen, Garivait, Bonnet, and Pongpullponsak (2013) found a fire intensity of 166.30 $\mathrm{kW} \mathrm{m}^{-1}$ in a deciduous forest of Doi Suthep-Pui National Park, which was lower than that reported in this study, despite the fact that the fuel load reported by Junpen et al. (2013) was similar to that of the mixed deciduous forest reported in this study (3.88 $\mathrm{t} \mathrm{ha}^{-1}$ ). This may be due to lower relative humidity and high wind speed in the present study, which helps with the combustion of fuel and increased fire intensities. Moreover, Junpen et al. (2013) did not mention the slope of the sampled terrain, as it can highly influence the fire intensity. The present study was in an area located on a very steep slope (>35\% gradient) and this resulted in a high rate of fire spread and hence higher fire intensity.

\subsection{Highland fire risk maps}

The fire risk maps of Thailand, Northern Thailand, Myanmar, and Lao PDR are shown in Figure 1. 


\begin{tabular}{|c|c|c|c|c|c|c|c|}
\hline Study & Land use & Fire tempe & ture $\left({ }^{\circ} \mathbf{C}\right)$ & Fuel con- & Fire behaviour & & \\
\hline site & & Maximum & Average & $\begin{array}{l}\text { sumption } \\
(\%)\end{array}$ & $\begin{array}{l}\text { Rate of fire } \\
\text { spread } \\
\left(\mathrm{m} \mathrm{min} \mathrm{min}^{-1}\right)\end{array}$ & $\begin{array}{l}\text { Fire } \\
\text { intensity } \\
\left(\mathrm{kW} \mathrm{m}^{-1}\right)\end{array}$ & $\begin{array}{l}\text { Flame } \\
\text { length } \\
\text { (m) }\end{array}$ \\
\hline \multirow{6}{*}{$\begin{array}{l}\text { Nan } \\
\text { province }\end{array}$} & Corn farm & 629 & 544.9 & 93 & 5.61 & 562.06 & 1.42 \\
\hline & Upland rice farm & NA & NA & NA & NA & NA & NA \\
\hline & 1-yr swidden farm* & NA & NA & NA & NA & NA & NA \\
\hline & 5-yr swidden farm* & 756 & 447.4 & 87 & 1.12 & 3202.5 & 12.82 \\
\hline & Abandoned highland & 708 & 349.5 & 47 & 1.26 & 893.2 & 7.13 \\
\hline & Mixed deciduous forest & 799 & 743.77 & 91 & 4.68 & 463.83 & 1.34 \\
\hline
\end{tabular}

Remarks: * indicates no burning. NA implies not applicable.

TABLE 2. Fire temperature and behaviour descriptors in the highland areas of Thailand.

These were produced using a newly available online beta tool provided by FAO OpenForis, called EarthMap (https://earthmap.org/). Even though the software is in its beta phase, the results look promising with high quality and rich data sources from lead agencies such as NASA and European Space Agency (ESA). The risk map is also dynamic, with maps modified based on additional high-quality information obtained from MODIS satellite products. Such fire risk maps can help to determine human activities to a higher degree of accuracy as burnt patches detected by satellites indicate where humans usually use fires. Information about the burnt area is better than details about active fires (hotspot) as a hotspot is just a point located in the middle of a pixel and does not tell how big a particular fire is. Moreover, such information can be uploaded and a user with an internet connection can access the maps and focus on a specific area of interest to explain the practice in more detail if needed.

EarthMap (version 1.0.0) is a tool to analyze past environment and climate based on the Google Earth Engine and developed in collaboration with the Government of Germany through The International Climate Initiative (IKI) of the Federal Ministry of the Environment Nature Conservation and Nuclear Safety. New risk maps are shown in Figure 2. The carbon maps from fire emissions during the months from January to April for 2018, 2019, and 2020, in the upper ASEAN region, are shown in Figure 3.

\subsection{Understanding the meteorology and air} pollutant emission from fire in the study domain through climatology, measurements, modelling, and climate change scenarios

This study focused on two constituents that can make aerosols and result in unhealthy levels of surface particulate matter (PM). These are the mixing layer (ML) height and the levels of PM (PM10 and PM2.5) emissions from the surface. We focused on the months of February, March and April of 2018, which are the months during which PM2.5 surface emissions increased and were at a maximum in Chiang Mai, northern Thailand. As seen in Figure 4, the monthly mean and median diurnal (daily) variations (blue and green lines) in ML height differ significantly between February (Figure 4A), March (Figure 4B), and April (Figure 4C).

In February (Figure 4A), the ML height gradually increases from oo local time and reaches the first peak at around 08 local time. After that, the ML height decreases and reaches a minimum value around noon. The ML height increases again and stays at a maximum value until 18 local time. It then gradually decreases during the night. Since the ML height acts like a cover inhibiting the dispersion of air pollutants, higher ML heights usually result in a lower surface PM, and vice versa, during the dry season. This can also be observed during the month of April (Figure 4C). However, during March (Figure $4 \mathrm{~B})$, the diurnal variation amplitude in ML height is significantly smaller. We hypothesize that this may be due to aerosol-meteorology interactions. 


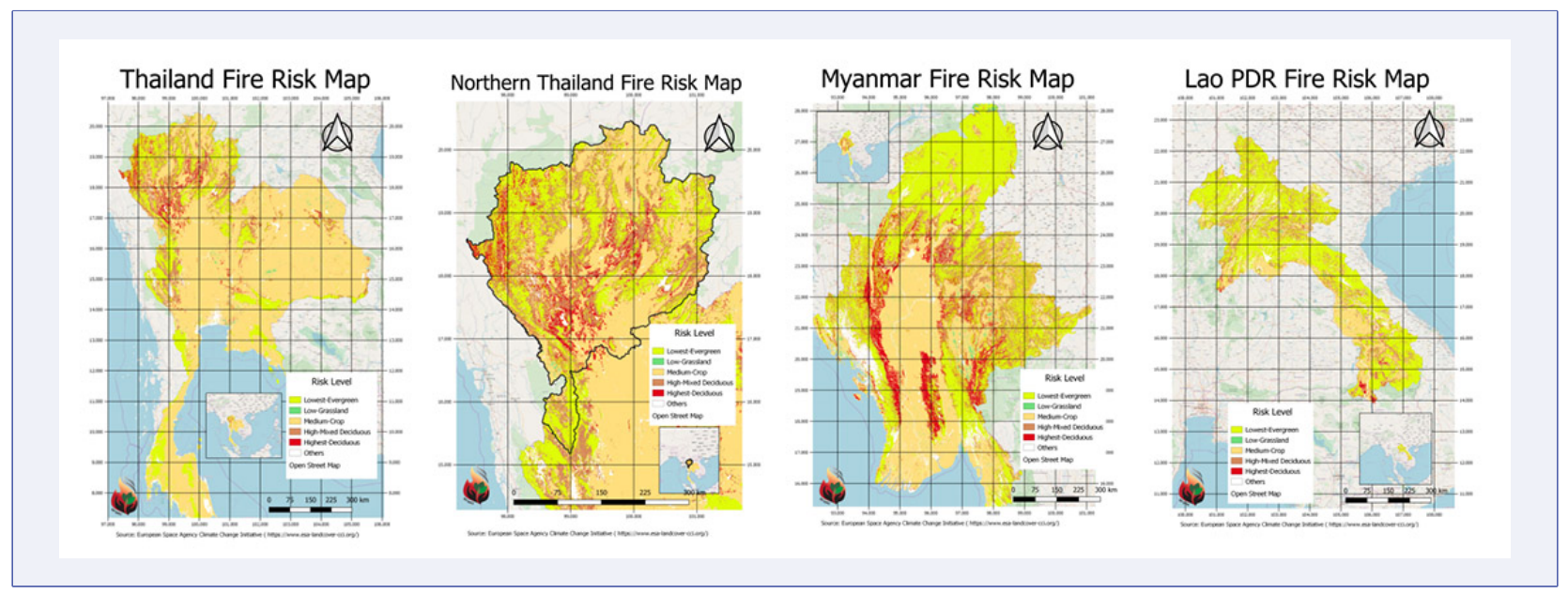

FIGURE 1. Constructed fire risk maps of Thailand, Northern Thailand, Myanmar, and Lao PDR (Source: European Space Agency Climate Change Initiative, https://climate.esa.int/en/).

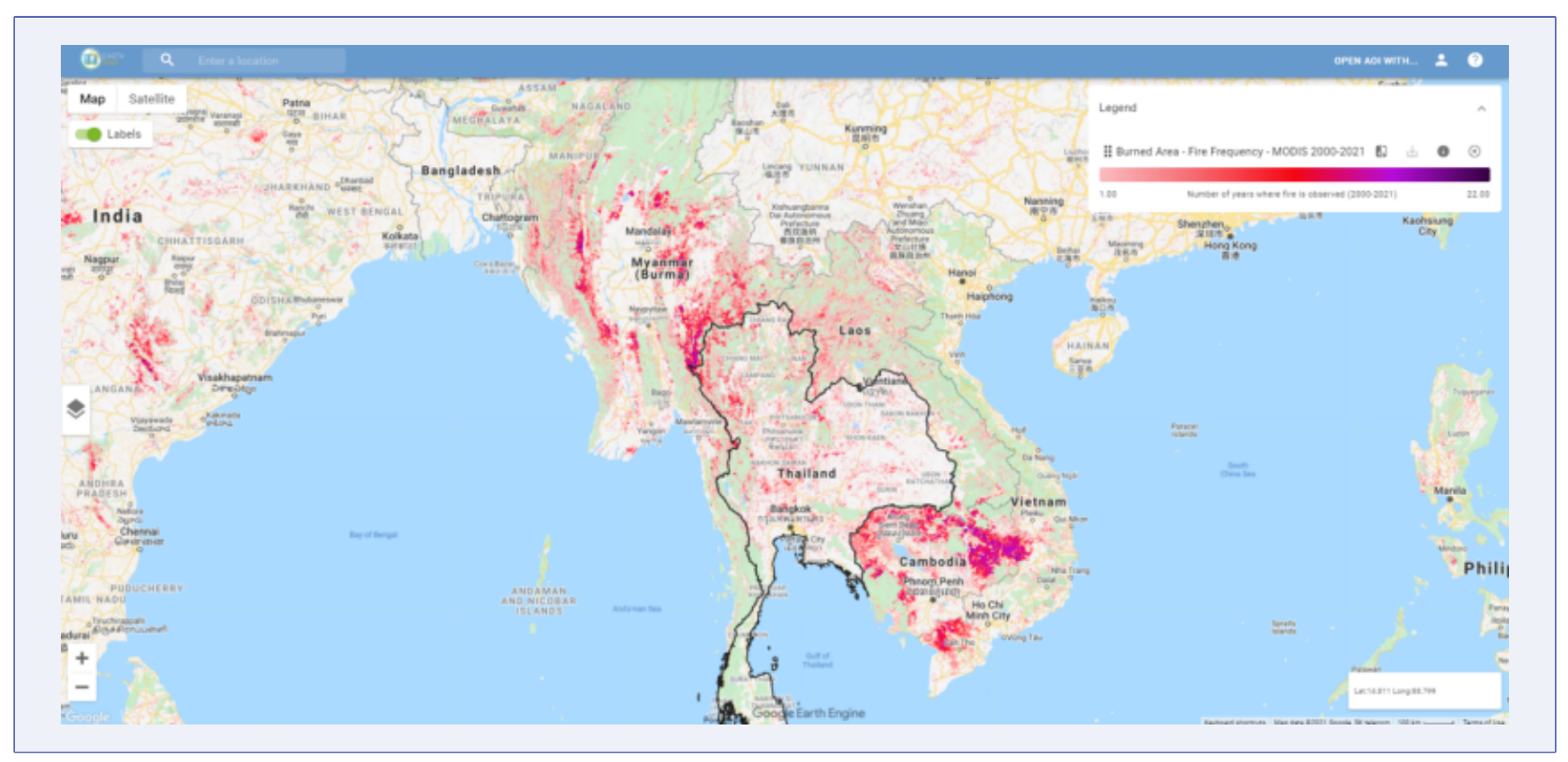

FIGURE 2. Upper ASEAN Risk Map by overlaying 22 years of burned areas as determined through MODIS (Source: https://earthmap.org/an d https://lpdaac.usgs.gov/products/mcd64a1voo6/).

\subsubsection{Meteorology effects on aerosol or particulate matter concentrations}

If surface particulate matter emissions reach an exceptionally high level, it may also affect the local meteorology. In particular, it may affect the diurnal variation of ML height, such as that observed during March 2018. This hypothesis was tested during the PLUME experiment as part of the 2019 7-SEAS project deployment during March 2019 in Fang District, Chiang Mai, northern Thailand, close to the border with Myanmar, where extensive particulate matter emissions were observed during this period. In theory, if there is a significant level of aerosols (particularly absorbing aerosols such as black carbon) emitted from the surface to the atmosphere, this will increase the ambient PM concentration in the air (Tao et al., 2020). If the aerosols are absorbed naturally, it will warm up the atmosphere near the top of the ML and cool the surface due to a dimming effect caused by the absorption of the aerosols. A cool surface and a warm top ML induce a temperature inversion that may suppress the development of the ML height and trap the air pollutants near the surface. This was observed in our LiDAR experiment and is depicted in Figure 5. 


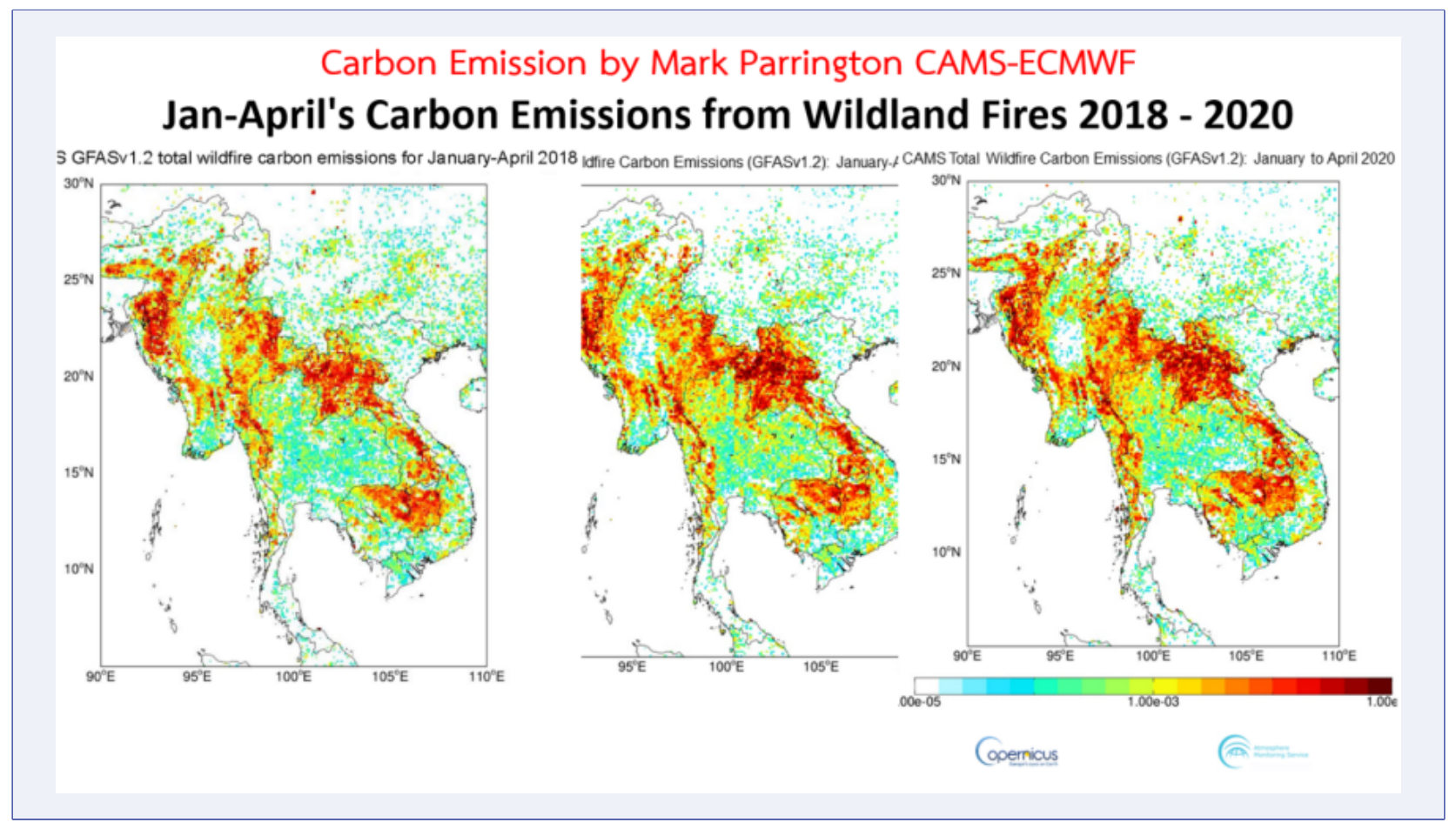

FIGURE 3. Combined maps of carbon emissions in the upper ASEAN region during January-April from wildland fires of years 2018 (left panel), 2019 (middle panel), and 2020 (right panel) (Source: Mark Parrington, GFAS-CAMS-ECMWF).
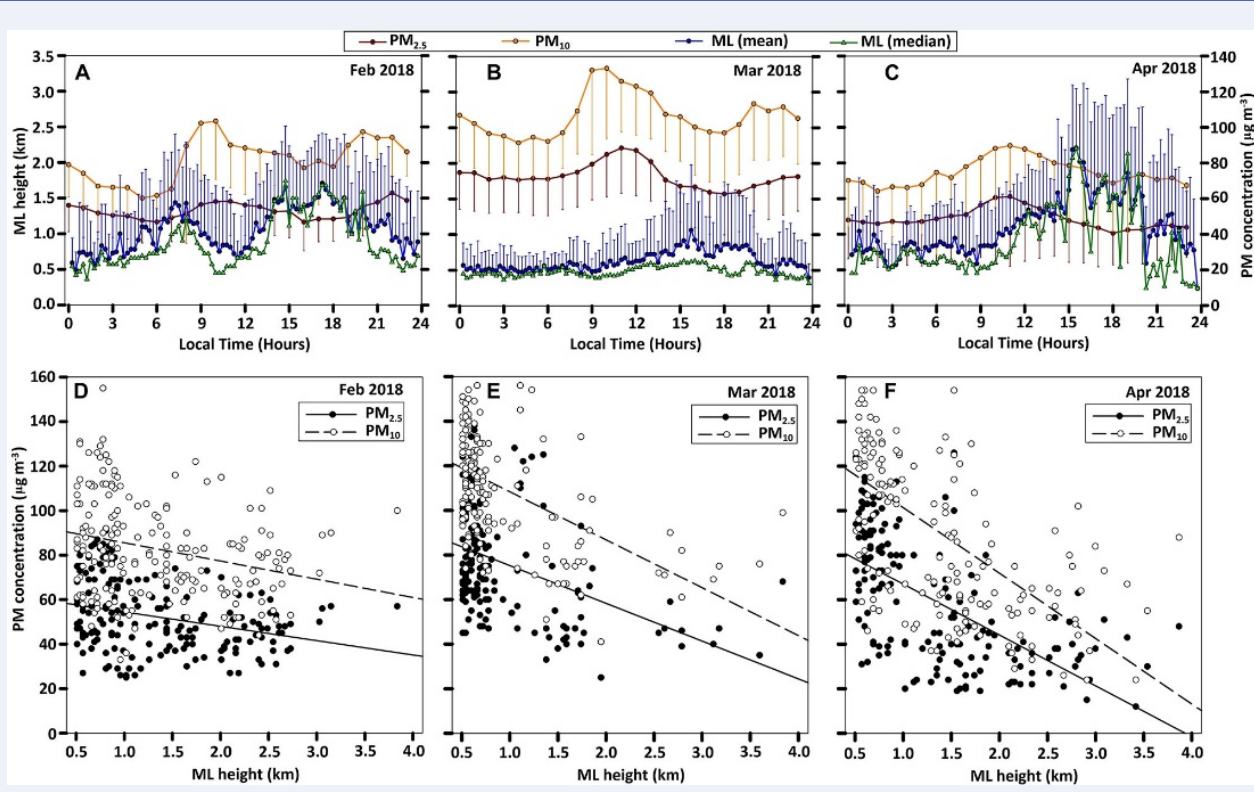

FIGURE 4. The effect of variability in mixing layer height (ML) on the surface PM2.5 concentrations (Solanki et al., 2019).

\subsection{Encouraging people participation in fire and} smoke management using concepts of Integrated Forest Fire Management (IFFM)

\subsubsection{Agricultural activities and forest resource} utilization by humans causing forest fires

The growth of agro-industry has led to a reduction in forest area through burning to expand farmlands. Farmers use fire for land preparation as it is an easy and low-cost approach. Several communities, particularly in the upper northern Thailand, use fire for farm management and integrate it into their livelihoods and traditions.

Hin Lad Nai Community is a Karen community located in the Huay Hin Lad Nai valley of the Khun Chae National Park, at an elevation of $900 \mathrm{~m}$ above sea level (masl) in the Wiang Pa Pao District, 


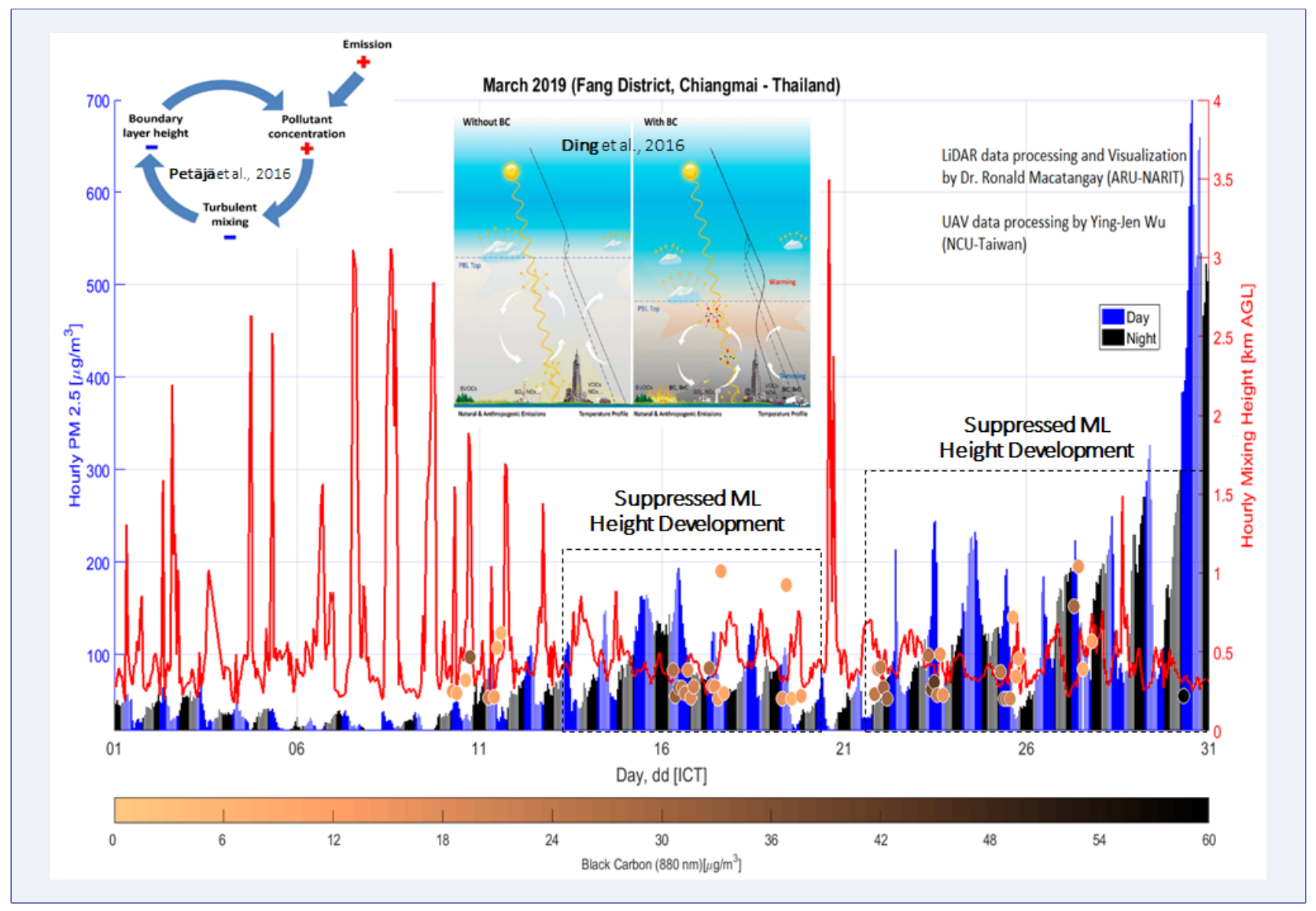

FIGURE 5. Suppressed mixing layer (ML) height development (red line; right axis) due to a significant amount of PM2.5 (black and blue bars; left axis) and maximum black carbon (brown dots; colour bars) concentration and altitude (right axis). Source: Climate Change Data Center-Chiang Mai University 2019, National Central University-Taiwan 2019, Petäjä et al. (2016) and Ding et al. (2013) .

Chiang Rai Province. The community has unique approaches to manage land use and forest fire, which are different from other communities. The community uses a combination of land-use and forest area zonation as agreed among its community members to manage the forest area and its resources. These approaches have led to sustainable farming, an efficient management of forest fires and reduction in selling of land to outsiders or changing land ownership, which one cannot sell to other, but can be transferred within the family members. To manage forest fires and prevent haze pollution, the community adopted IFFM through the participation of community members, youth, government authorities, researchers, and civil society organizations; and by applying a combination of traditional knowledge and local wisdom with new technologies and innovation to develop a CBFiM plan. The community established a board to debate on policies and make decisions on any activities related to utilizing forest area and its resources. For example, if a community member would want to cut trees in the forest to build a house, they would need permission from the community board. For agriculture, the community uses rotational farming. Farmers divide planting plots into 7 sub-plots and only use one plot per year, leaving the rest for natural recovery. The farmers would use the same plot or a smaller area for farming each season without expanding the planting area into the forest. All the plots are recorded in a database and mapped to prove that the agricultural area has not expanded over time. This practice is different from the usual shifting cultivation in other regions practicing highland agriculture.

Through the partnership, participatory process and concrete CBFiM action plan, the community developed ownership, acceptance and cooperation, which allows for sustainable agriculture practices while conserving natural resources and preventing 
forest fire. Moreover, the community established a community fund to manage forest fires, which benefits from selling forest products such as bamboo shoots and honey. The community agreed to allocate 0.25 THB per kilogram of sold bamboo shoots and 20 THB per bottle or kilogram from selling honey to the community fund. The fund was used to buy equipment for the construction of firebreaks, covering the cost for fire patrols during January and April every year, and buying food for the members who are involved with the fire management activities.

Key strengths of the Hin Lad Nai community that have contributed to the success of forest fire are community knowledge, local wisdom and traditions, which teach the people to love and conserve the natural resources. The knowledge includes sustainable agriculture, knowledge about indigenous vegetation, importance of biodiversity and ancient traditions, which have been passed on from generation to generation. In addition, the community is open to learning and adopting new technologies and knowledge. For example, the community adopted a mobile application to monitor forest fire in the community and the surrounding area. The community also developed a database of the natural resources using Geographic Information Systems and developed a map to classify the forest types, land use types, firebreak locations and eco-tourism areas. The community actively participates in training and capacity development activities organized by the government and civil society organizations. Therefore, the community became a part of the knowledge and experience exchange network, which enabled them to receive news and remain up-to -date on the current situations.

\section{CONCLUSION}

In the highlands, local people still practice burning of residue after harvesting, and the fuel loads on the higher side, and with a steep slope, the fire intensity is high. Fire risk maps of Thailand, northern Thailand, Myanmar, and Lao PDR can help us classify the high-risk areas to be used as references while determining the areas with potential fire risk. We focused on the annual haze events that occur over the upper highlands of Indochina. We used a mini micro-pulse LiDAR system to complement the existing surface air pollution monitoring systems. We also quantified the diurnal variability of the ML height over the Chiang Mai valley from April 2017-March 2018. The maximum ML heights during April, May and June reached altitudes of up to $3 \mathrm{~km}$ during July, August and September; $2 \mathrm{~km}$ during October, November and December; and 1.5 km during January and February. During March, the ML height was generally at its lowest, at around $500 \mathrm{~m}$ from the ground. The role of the ML height in the variations of air pollutant concentrations over the Chiang Mai valley was significantly evident during the dry season. High ML heights produced lower air pollutant concentrations near the surface, and lower ML heights produced higher air pollutant concentrations near the surface. During March, when there were significant emissions of absorbing aerosols, we observed that the development of ML height was suppressed, causing air pollutant accumulation near the surface due to an aerosolmeteorology feedback mechanism.

The success of forest fire management in the Hin Lad Nai Community was due to an integration of strong traditional knowledge about the conservation of natural resources and farming practices, and new technology and knowledge to manage forest fires. Key factors contributing to the community participation included: 1) benefit from participation; 2) channels and opportunities to participate; 3 ) opportunity to be involved in defining the objectives and scopes of work; 4) community leaders; 5) support from the government and other parties; and 6) integration of human rights, livelihoods and traditional aspects. Furthermore, participation in knowledge exchange platforms enhanced the understanding further and led to a successful and sustainable IFFM.

\section{ACKNOWLEDGEMENTS}

We would like to thank the following: Royal Forest Department (RFD), Department of National Parks, Wildlife and Plants Conservation 
(DNP), Asian Forest Cooperation Organization , Department of Community Forestry and Rural Development, Faculty of Forest Science, National University of Laos, Department of Forestry of Lao PDR, Upper ASEAN Wildland Fire Special Research Unit, Forestry Research Center, Faculty of Forestry, Kasetsart University, Disaster Mitigation Working Group (DMWG) of Asia Pacific Advanced Network (APAN), and National Astronomical Research Institute of Thailand (Atmospheric Research Unit of NARIT), for their generous support and kind help.

\section{REFERENCES}

Akaakara, S. (1996). Forest Fire Control in Thailand. Bangkok: Forest Fire Control Division, Royal Forest Department.

Andrews, P.L. (1980). Testing the fire behavior model. In Proceedings Sixth Conference on Fire and Forest Meteorology, 22-24 April 1980. Seattle, WA: Society of American Foresters.

Brooks, I.M. (2003). Finding boundary layer top: Application of a wavelet covariance transform to lidar backscatter profiles. Journal of Atmospheric and Oceanic Technology, 2o(8), 1092-1105. doi:10.1175/15200426(2003)020<1092:FBLTAO>2.0.CO;2

Byram, G.M. (1959). Combustion of forest fuels. In Davis, K. (Ed.), Forest Fire: Control and Use (pp. 61-89). New York: McGraw-Hill.

Ding, A.J., Fu, C.B., Yang, X.Q., Sun, J.N., Petäjä, T., Kerminen, V.M., ... Kulmala, M. (2013). Intense atmospheric pollution modifies weather: a case of mixed biomass burning with fossil fuel combustion pollution in eastern China. Atmospheric Chemistry and Physics, 13(20), 10545-10554. doi:10.5194/acp-1310545-2013

García-Franco, J.L., Stremme, W., \& Bezanilla, A. (2018). Variability of the Mixed-Layer Height Over Mexico City. Boundary-Layer Meteorology, 167, 493-507. doi:10.1007/s10546-018-0334-x

Junpen, A., Garivait, S., Bonnet, S., \& Pongpullponsak, A. (2013). Fire spread prediction for deciduous forest fires in Northern Thailand. Science Asia, 39, 535-545. doi:10.2306/scienceasia1513-1874.2013.39.535
Lizotte, P.L., Savoie, P., \& Champlain, A.D. (2015). Ash content and calorific energy of corn stover components in Eastern Canada. Energies, 8(6), 4827-4838. doi:10.3390/en8064827

Petäjä, T., Järvi, L., Kerminen, V.M., Ding, A.J., Sun, J.N., Nie, W., ... Kulmala, M. (2016). Enhanced air pollution via aerosol-boundary layer feedback in China. Scientific Reports, 6(1), 18998 doi:doi.org/10.1038/srep18998

Seibert, P. (2000). Review and intercomparison of operational methods for the determination of the mixing height. Atmospheric Environment, 34(7), 10011027. doi:10.1016/s1352-2310(99)00349-0

Solanki, R., Macatangay, R., Sakulsupich, V., Sonkaew, T., \& Mahapatra, P.S. (2019). Mixing layer height retrievals from MiniMPL measurements in the Chiang Mai valley: implications for particulate matter pollution. Frontiers in Earth Science, 7, 308. doi:10.3389/feart.2019.00308

Sompoh, B. (1998). Fuel complex in dry dipterocarp and mixed deciduous forests at Huai Kha Khaeng Wildlife Sanctuary, Changwat Uthai Thani. (Doctoral dissertation, MSc thesis, Faculty of Forestry, Kasetsart Univ, Thailand).

Stull, R.B. (1988). An introduction to boundary layer meteorology, volume 13 of Atmospheric Sciences Library. Dordrecht: Kluwer Academic Publishers. doi:10.1007/978-94-009-3027-8

Tao, J., Surapipith, V., Han, Z., Prapamontol, T., Kawichai, S., Zhang, L., ... Zhang, R. (2020). High mass absorption efficiency of carbonaceous aerosols during the biomass burning season in Chiang Mai of northern Thailand. Atmospheric Environment, 240, 117821. doi:10.1016/j.atmosenv.2020.117821

Tsutsumi, T., Yoda, K., Sahunalu, P., Dhanmanonda, P., \& Prachaiyo, B. (1983). Forest: felling, burning and regeneration. In Kyuma, K., \& Pairintra, C. (Eds.), Shifting cultivation (pp. 13-62). Kyoto: Kyoto University.

Wanthongchai, K., Tarusadamrongdet, V., Chinnawong, K., \& Sooksawat, K. (2013). Fuel properties and fire behaviour characteristics of prescribed fire in pine-dominated forests at Nam Nao National Park, Thailand. International Journal of Wildland Fire, 22(5), 615-624. doi:10.1071/WF11183 